\title{
ВВЕДЕНИЕ АНАЛИЗА БЮДЖЕТНЫХ РАСХОДОВ В БЮДЖЕТНЫЙ ПРОЦЕСС ГЕРМАНИИ
}

\begin{abstract}
Аннотация. В статье рассмотрен германский опыт применения новой бюджетной технологии - анализа бюджетных расходов (АБР). К 2019 г. она стала постоянной и обязательной составной частью подготовки бюджета, в её основу положена система взаимосвязанных понятий, разработанных авторитетными спечиалистами ОЭСР, Еврокомиссии и Еврогруппь. Цикл продолжается в течение полутора лет, начинаясь ежегодно в марте и заканчиваясь в августе следующего года. Растёт охват расходов и отраслевых министерств/ведомств. Германский АБР нацелен на перестройку структуры расходов, является выборочнымм и выражается в основном в функииональной экономии. В результате внедрения АБР создана действующая на уровне высшего политического руководства система обязательного одновреме́нного рассмотрения вариантов экономии расходов на действующие обязательства и вариантов выделения средств на принимаемые обязательства. Тем самым обеспечивается соблюдение максимального лимита совокупных расходов, которое необходимо для поддержания стабильности госфинансов.
\end{abstract}

Ключевые слова: анализ бюджетных расходов, АБР, приоритизация расходов, выборочный АБР, функииональная экономия, ичикл АБР.

До глобального финансового кризиса 2007-2008 гг. анализы бюджетных расходов (АБР) проводились лишь в отдельных странах-пионерах (Великобритании, Дании, Канаде, Нидерландах, Финляндии, Швеции) в периоды, когда возникала необходимость снижения расходов бюджета в целях консолидации (оздоровления) государственных финансов (уменьшения абсолютных и относительных размеров бюджетного дефицита, госдолга и процентных выплат по госдолгу). В 2007-2012 гг. применение АБР существенно расширилось из-за обострения проблемы консолидации бюджета во многих странах. С 2013 г., по мере укрепления устойчивости госфинансов, АБР стали использоваться как средство, позволяющее не только выявлять пути снижения расходов, но и перестраивать структуру последних, что обусловило дальнейшее повышение интереса к этой технологии. АБР внедрены уже в 66\% (23 из 35) стран Организации экономического сотрудничества и развития (ОЭСР), в ближайшее время этот показатель возрастет до $88 \%{ }^{1}$.

Особую роль в послекризисном распространении АБР сыграла поддержка со стороны Евросоюза (ЕС) и стран еврозоны (Еврогруппы). Еврокомиссия стала включать проведение АБР в перечни своих рекомендаций странам ЕС при реализации структурных реформ. С 2015 г. Служба поддержки структурных реформ, действующая под эгидой Еврокомиссии, в сотрудничестве с Департаментом бюджетных вопросов Международного валютного фонда

(C) Грачева Мария Владимировна - кандидат экономических наук, ведущий научный сотрудник НИ ИМЭМО им. Е.М. Примакова РАН. Aдpec: 117997, Россия, Москва, ул. Профсоюзная, д. 23. E-mail: mgracheva@mail.ru. SPIN-код РИНЦ: 4779-8130.

DOI: http://dx.doi.org/10.15211/vestnikieran22019106112

${ }^{1}$ Spending review. In: Government..., 2017; Spending review. In: 2016 OECD..., 2017; Quality of public finances..., 2017. 
оказывает консультационную поддержку странам ЕС в применении АБР. В 2016 г. на совещании министров финансов Еврогруппы была принята резолюция о необходимости активного внедрения АБР ${ }^{1}$. Весьма вероятно, что скоро технология АБР станет обязательной составной частью подготовки бюджета в развитых странах.

Рассмотрим, как происходит внедрение АБР в Германии. Положение о встраивании в бюджетный процесс новых элементов в виде тщательных анализов доходов и расходов впервые было внесено в договор о создании коалиционного правительства 2013 г. $^{2}$ В 2014 г. эксперты ОЭСР провели глубокое исследование федеральной бюджетной системы ФРГ, присвоили ей в целом высокую оценку и сформулировали рекомендации по её совершенствованию, поставив на первое место введение АБР ${ }^{3}$. В коалиционном договоре 2018 г. была подчёркнута необходимость развития такой практики ${ }^{4}$.

Особенности проведения АБР в Германии представлены в обзорах и других публикациях Министерства финансов (МФ) $)^{5}$. ФРГ является новичком в применении этой технологии: к началу 2019 г. прошли только три цикла АБР.

АБР (spending review) - это процесс разработки и принятия мер по экономии бюджетных расходов на базе систематического и тщательного изучения расходов на действующие обязательства ${ }^{6}$. В Германии АБР применяется в настоящее время только к федеральному бюджету, продолжительность цикла составляет полтора года.

АБР охватывает четыре этапа: (0) создание концепции, (1) определение параметров, (2) разработка вариантов экономии расходов, (3) принятие решения о выборе конкретных мер. Для обеспечения прозрачности АБР публикуется отчёт о его проведении.

Ключевыми действующими лицами в рамках АБР являются: высшее политическое руководство (ВПР), участвующее в АБР - на нулевом и первом этапах (главная роль), а также на третьем этапе (эксклюзивная роль); МФ - на нулевом, первом и втором этапах; отраслевые министерства/ведомства (OMB) и внешние эксперты - на втором этапе.

ВПР, участвующее в АБР - это лица исполнительной власти, обладающие главными бюджетными полномочиями в стране. Прежде всего, это президент/премьер-министр/кабинет министров (в зависимости от системы исполнительной власти) и министр финансов. Если администрации президента/премьер-министра имеют серьёзные бюджетные полномочия, они также включены в АБР. В Германии к ВПР, участвующему в АБР, относятся федеральный кабинет министров (ФКМ), а также руководители высшего звена Ведомства федерального канцлера, МФ и Министерства экономики и энергетики, входящие в руководящий комитет (РК) АБР.

Нулевой этап. Концепция каждого цикла германского АБР разрабатывается специально созданным для этого в июне 2014 г. структурным подразделением МФ, а утверждается на заседании ФКМ. Она содержит формулировку цели/целей АБР, перечень мер по экономии расходов, указание о наличии/отсутствии конкретных объектов АБР.

Целями АБР могут быть: а) укрепление контроля над уровнем совокупных бюджетных расходов и б) совершенствование приоритизации (перестройка структуры) расходов. Первая цель играет главную роль в периоды нестабильности/кризиса госфинансов, вторая - в периоды стабильности/улучшения состояния госфинансов; в то же время АБР может иметь две це-

\footnotetext{
${ }^{1}$ Wendling, 2016; Eurogroup statement..., 2016.

${ }^{2}$ Deutschlands Zukunft..., 2013. S. 88.

${ }^{3}$ Budget Review..., 2014. P. 12.

${ }_{5}^{4}$ Ein neuer Aufbruch..., 2018. S. 66.

5 Abschlussberichte..., 2016, 2017, 2018; Bach, 2017; Spending reviews..., 2016. S. 14-21; Wirkungsorientierung..., 2017. S. 34-40.

${ }^{6}$ В данной статье используется система взаимосвязанных понятий, сформулированных авторитетными специалистами ОЭСР, Еврокомиссии и Еврогруппы (определение, этапы, цели АБР, меры по экономии расходов и т.д.).
}

Научно-аналитический вестник ИЕ РАН, 2019, №2 
ли. Поскольку ФРГ не стоит сейчас перед острой проблемой бюджетной консолидации (с 2014 г. федеральный бюджет является бездефицитным), все три цикла германского АБР были сосредоточены на второй цели.

Меры по экономии бюджетных расходов могут быть функциональными, стратегическими и комбинированными. Функциональная экономия (functional savings) - это введение нового способа предоставления государственной услуги, обеспечивающего снижение затрат на оказание услуги при сохранении прежних параметров количества и качества услуги ${ }^{1}$. Стратегическая экономия (strategic savings) - это ликвидация госуслуги (или снижение её количества/качества) и/или отмена/сокращение социальной выплаты ${ }^{2}$. В германском АБР предпочтение отдаётся функциональной экономии.

При наличии конкретных объектов АБР является выборочным $\left(\right.$ selective $\left.^{3}\right)$, при отсутствии таких объектов - широким (comprehensive). Объектами выборочного АБР могут стать отдельные бюджетные программы/процессы/организации, а также горизонтальные программы (бюджетные программы, реализуемые рядом бюджетных организаций) и горизонтальные процессы (бюджетные процессы, осуществляемые многими или всеми бюджетными организациями - например, госзакупки или управление кадрами). Широкий АБР сложнее и требует больше ресурсов, но обеспечивает более значительные показатели охвата и экономии расходов госбюджета, чем выборочный АБР.

Необходимость в широком АБР возникает, если правительство должно быстро и сильно сократить совокупные госрасходы или кардинально изменить их структуру в целях: а) достижения бюджетной консолидации, б) уменьшения госсектора в экономике, в) подготовки глубокой перестройки расходов после прихода к власти нового правительства, в корне не согласного с предыдущей бюджетной политикой. В «спокойных» условиях лучше использовать выборочные АБР, именно они и проводятся в Германии.

Первый этап. Параметры германского АБР (целевые количественные показатели экономии расходов, перечень объектов в случае проведения выборочного АБР, критерии поиска вариантов экономии расходов, календарь процедур) утверждаются на заседании ФКМ. Объекты выборочного АБР определяются либо по усмотрению ВПР (например, в перечень включаются бюджетные программы/процессы/организации, к которым возникает множество критических вопросов у общественности и парламента), либо в рамках равномерного цикла (например, в течение трёх лет ежегодно анализируется треть бюджетных организаций). Возможно и совмещение указанных способов. Критерии поиска вариантов формулируются обычно в виде вопросов, на которые должны ответить специалисты команды, проводящей АБР (например: Является ли анализируемая деятельность существенно необходимой для решения главных задач правительства? Нужно ли правительству финансировать эту деятельность? Обладает ли эта деятельность существенной ценностью для экономики страны?). Объекты АБР для бюджета на послеследующий год $(t+2)$ утверждаются вместе с параметрами федерального бюджета на следующий год $(t+1)$ на заседании ФКМ, которое проводится ежегодно в марте текущего года $(t)$.

Bторой этап. Варианты экономии расходов определяются в Германии на базе совместной модели, в которой ОМВ играют весьма заметную роль. В других странах используются также модель снизу вверх (ОМВ играют более значительную роль, чем в совместной модели) и модель сверху вниз (ОМВ играют более скромную роль, чем в совместной модели).

\footnotetext{
${ }^{1}$ Другие названия функциональной экономии - операционная экономия (operational savings), экономия за счёт повышения эффективности (efficiency savings).

${ }_{3}^{2}$ Другое название стратегической экономии - сокращение результатов деятельности госорганов (output savings).

3 Другие названия выборочного АБР - целевой (targeted), узкий (narrow).
}

Научно-аналитический вестник ИЕ РАН, 2019, №2 
Процесс разработки вариантов возглавляет РК АБР, председателем которого является замминистра, государственный секретарь МФ по вопросам бюджета. Постоянными членами РК являются госсекретари Ведомства федерального канцлера и Министерства экономики и энергетики, а переменными членами - госсекретари тех OMB, чьи направления деятельности/программы/процессы внесены в перечень объектов текущего АБР. РК создает рабочие группы (РГ) по всем объектам АБР и составляет для них задания. Членами РГ являются сотрудники МФ и соответствующих ОМВ, могут быть приглашены внешние эксперты. Первое заседание РК в рамках цикла АБР проводится сразу после указанного выше мартовского заседания ФКМ.

РГ состоит обычно из 12 членов, в т.ч. в неё входят два сопредседателя (главы департаментов МФ и ОМВ), представители бюджетного и отраслевого департаментов ОМВ, представители стратегического и отраслевого департаментов МФ, приглашенные эксперты. Заседания РГ проводятся в МФ. Если оценки эффективности и результативности включённых в АБР бюджетных программ/процессов/организаций уже имеются, используются их итоги. В случае отсутствия таких оценок, они проводятся по запросам РГ. Особое внимание уделяется проверке соответствия целей осуществляемых расходов целям текущей государственной политики (это весьма актуально для старых, давно действующих программ/процессов/организаций). На основе указанных оценок РГ определяют варианты экономии расходов и составляют отчёты с наборами этих вариантов, которые могут противоречить друг другу. Среди членов РГ никто не обладает правом вето. До конца года $t$ РГ выполняют задания, проводя по 510 заседаний, в этот период РК получает от всех РГ промежуточные отчеты и рассматривает их на своем втором заседании.

Tретий этап. Решения о принятии конкретных мер по экономии расходов к исполнению принимает ФКМ по предложениям РК. РК составляет свои предложения для ФКМ по расходам на год $t+2$ на своём третьем заседании в феврале года $t+1$, рассматривая полученные к этому времени окончательные отчеты РГ и выбирая конкретные меры из тех вариантов, что были представлены в этих отчётах. В марте года $t+1$ с учётом полученных от РК предложений ФКМ утверждает основные параметры федерального бюджета на год $t+2$ и объекты АБР для бюджета на год $t+3$. В августе года $t+1$ МФ публикует отчет об АБР, проведённом в годы $t / t+1$.

Три цикла АБР, прошедшие к началу 2019 г. в Германии, представлены ниже в таблице. Первый цикл был нацелен на совершенствование приоритизации расходов, являлся выборочным, его результат выразился в комбинированном (как функциональном, так и стратегическом) сокращении расходов с перенаправлением сэкономленных сумм на другие сферы. Этот цикл стал пробным: он был проведен в ускоренном порядке, охватил лишь два ОМВ и весьма скромный объём расходов.

Второй цикл прошёл по графику, сохранил ту же цель и выборочный характер, в нём участвовали пять ОМВ, однако он не достиг требуемого результата, т.к. не были приняты решения об изменении объёма/структуры расходов в связи с необходимостью проведения мониторинга и углублённых оценок эффективности и результативности бюджетных программ.

И наконец, третий цикл оказался полноценным. Он начался и закончился вовремя (хотя некоторые процедуры были проведены с опозданием), повторил нацеленность и выборочность, прошёл с участием семи ОМВ, обеспечил функциональное изменение структуры расходов, объём включённых в него расходов достиг $1,5 \%$ расходной части федерального бюджета ${ }^{1}$ (по международным меркам это уже неплохой показатель ${ }^{2}$ ).

\footnotetext{
${ }^{1}$ Bach, 2017. S. 14.

2 Robinson, 2013. P. 39.
}

Научно-аналитический вестник ИЕ РАН, 2019, №2 
Таким образом, с каждым циклом растут охват расходов и ОМВ, в условиях профицита и стабильности бюджетной политики германский АБР сосредоточен на совершенствовании приоритизации расходов (а не на их сокращении на макроуровне), является выборочным и преимущественно функциональным. Важный урок относительной неудачи второго цикла необходимость установления надлежащего соотношения АБР с бюджетированием, ориентированным на результаты. Главной особенностью третьего цикла стало окончательное формирование АБР как неотъемлемого элемента бюджетного процесса в ФРГ.

В результате внедрения АБР в Германии создана система обязательного одновре́менного рассмотрения на уровне ВПР вариантов экономии расходов на действующие обязательст-ва и вариантов выделения средств на принимаемые обязательства. Традиционный бюджетный процесс слишком сильно сфокусирован на анализе предложений о новых расходах. В таких условиях осуществление старых расходов, ставших низкоэффективными, мало нужными, дав-но потерявшими свою изначальную полезность, становится опасным тормозом, поглощающим ограниченные государственные ресурсы. Встраивание АБР в бюджетный процесс в каче-стве системного (постоянного и обязательного) элемента позволяет принципиально изменить такую ситуацию, обеспечивая соблюдение максимального лимита совокупных расходов, край-не необходимого для поддержания стабильности госфинансов.

Новые бюджетные технологии - анализ бюджетных расходов и созданный недавно независимый бюджетный институт (Независимый консультативный комитет Стабилизационного совета ${ }^{1}$ - внесли важный вклад в повышение точности планирования федеральных расходов в ФРГ $\Gamma^{2}$.

Таблица

Объекты АБР в Германии и принятые по ним решения

\begin{tabular}{|c|c|}
\hline Объект & Решение \\
\hline \multicolumn{2}{|r|}{ 2015-2016 ГГ. } \\
\hline $\begin{array}{l}\text { БП*-1 «Содействие развитию комбинирован- } \\
\text { ных грузоперевозок» }\end{array}$ & $\begin{array}{l}\text { (1) Сократить расходы на БП-1 на } 20 \text { млн € ежегодно в 2017- } \\
2018 \text { гг., направить сэкономленные средства на реализацию } \\
\text { смежной БП в рамках того же ОМВ и оценить необходимость } \\
\text { восстановления финансирования в } 2019 \text { г. }\end{array}$ \\
\hline $\begin{array}{l}\text { БП-2 «Содействие развитию профессиональ- } \\
\text { ной мобильности молодежи стран ЕС» }\end{array}$ & $\begin{array}{l}\text { (2) Ликвидировать БП-2 с } 2017 \text { г. и направить сэкономленные } \\
\text { средства }(232 \text { млн } €) \text { на реализацию смежной БП в рамках того } \\
\text { же ОМВ. }\end{array}$ \\
\hline \multicolumn{2}{|r|}{ 2016-2017 Гг. } \\
\hline $\begin{array}{l}\text { Жилищчное хозяйство: } \\
\text { (a) расходы федерального бюджета (2,5 млрд } € \\
\text { в 2018-2019 гг.) на компенсацию федеральным } \\
\text { землям средств, выплачивавшихся до } 2007 \text { г. } \\
\text { из федерального бюджета на поддержку соци- } \\
\text { ального жилья**; } \\
\text { (б) расходы федерального бюджета (446 млн } € \\
\text { в 2018-2019 гг.) на выплату дотаций физлицам } \\
\text { на приобретение/строительство собственного } \\
\text { жилья. }\end{array}$ & $\begin{array}{l}\text { (1) Не сокращать компенсацию, вести тщательный мониторинг } \\
\text { мероприятий, осуществляемых федеральными землями в рам- } \\
\text { ках ее использования. } \\
\text { (2) Признать недостаточной проведенную ранее оценку эффек- } \\
\text { тивности и результативности программы жилищных дотаций, } \\
\text { провести по заказу МФ и Министерства окружающей среды } \\
\text { углубленную оценку, до получения ее итогов не сокращать } \\
\text { дотации. }\end{array}$ \\
\hline $\begin{array}{l}\text { Энергетика и климат: } \\
\text { расходы федерального бюджета ( } 87 \text { млн } € \text { в } \\
2015-2016 \text { гг.) на поддержку деятельности ме- } \\
\text { стных коммун по защите климата, экономии } \\
\text { энергии и поворота к возобновляемой энерге- } \\
\text { тике. }\end{array}$ & $\begin{array}{l}\text { (3) Провести полномасштабную оценку эффективности и ре- } \\
\text { зультативности программ поддержки деятельности местных } \\
\text { коммун в сферах энергетики и климата, выявить возможные } \\
\text { противоречия и дублирование, до получения итогов оценки не } \\
\text { сокращать поддержку. }\end{array}$ \\
\hline
\end{tabular}

\footnotetext{
${ }_{1}^{1}$ Грачева, Новые технологии ..., 2018.

2 Грачева, Эффективность ..., 2018.
}

Научно-аналитический вестник ИЕ РАН, 2019, №2 


\begin{tabular}{|c|c|}
\hline \multicolumn{2}{|r|}{ 2017-2018 ГГ. } \\
\hline $\begin{array}{l}\text { Госзакупки стандартных массовых товаров и } \\
\text { услуг (СМТУ): } \\
\text { расходы федерального бюджета (1,45 млрд € в } \\
2016 \text { г.) на приобретение СМТУ для нужд } 75 \\
\text { федеральных организаций госуправления } \\
\text { (ФОГУ). }\end{array}$ & $\begin{array}{l}\text { (1) Повысить долю электронного федерального универмага } \\
\text { (ЭФУ)*** в госзакупках СМТУ (она составляет лишь } 16 \% \text {, при } \\
\text { этом согласно рекомендациям ОЭСР, централизация и цифро- } \\
\text { визация являются важными способами подъема эффективности } \\
\left.\text { госзакупок }{ }^{1}\right) \text {. } \\
(2) \text { Обеспечить централизацию госзакупок СМТУ внутри } \\
\text { ФОГУ: введение должности центрального уполномоченного, } \\
\text { объединение и гармонизация заявок на СМТУ, постоянное ин- } \\
\text { формирование ФОГУ о предложениях ЭФУ, регулярные встре- } \\
\text { чи координаторов закупок и т.д. } \\
\text { (3) Ввести в ФОГУ обязательные процедуры: использование } \\
\text { ТДЗ***, участие в проводимых секретариатом ЭФУ опросах, } \\
\text { регулярная передача в ЭФУ информации о своих потребностях } \\
\text { и о совершенных помимо ЭФУ закупках. } \\
\text { (4) Повысить эффективность деятельности ЭФУ и ЦОЗ*** пу- } \\
\text { тем: регулярного информирования ФОГУ обо всех нововведе- } \\
\text { ниях в работе ЭФУ; составления ежемесячных финансовых } \\
\text { отчетов о госзакупках СМТУ; цифровизации и стандартизации } \\
\text { обычных закупочных процедур в целях переориентации ме-- } \\
\text { неджеров по закупкам на управление спросом и изучение рын- } \\
\text { ка; увеличения доли электронных заявок на базе ТДЗ; состав- } \\
\text { ления регулярных обзоров о реализации заявок на базе ТДЗ; } \\
\text { подачи заявок на базе Тдз без предварительного уведомления; } \\
\text { повышения квалификации менеджеров по закупкам в сфере } \\
\text { законодательства о госзакупках и перехода от исключительно } \\
\text { ценовой к стратегической ориентации госзакупок. }\end{array}$ \\
\hline $\begin{array}{l}\text { Гуманитарная и переходная помощь: } \\
\text { расходы федерального бюджета (более } \\
3 \text { млрд } € \text { в } 2017 \text { г.) на согласованное решение } \\
\text { проблем преодоления кризисов, стабилизации } \\
\text { и сотрудничества с развивающимися странами. }\end{array}$ & $\begin{array}{l}\text { (5) Провести совместный анализ ситуации в кризисных странах } \\
\text { силами Министерства иностранных дел (МИД) и Министерства } \\
\text { экономического сотрудничества с развивающимися странами } \\
\text { (МЭС) и на его базе разработать концепцию планирования и } \\
\text { распределения средств, выделяемых на помощь указанным } \\
\text { странам. } \\
\text { (6) Ввести в практику представление парламенту докладов о } \\
\text { гуманитарной помощи и преодолении кризисов. } \\
\text { (7) Разработать согласованные между собой и с МФ директивы } \\
\text { о поддержке гуманитарной помощи (МИд) и преодоления кри- } \\
\text { зисов (МЭС). } \\
\text { (8) Ввести в МИД и МЭС процедуры оценки эффективности } \\
\text { политики в сферах гуманитарной помощи и преодоления кри- } \\
\text { зисов. }\end{array}$ \\
\hline
\end{tabular}

* БП - бюджетная программа.

** Компенсация действует до конца 2019 г., затем федеральные земли получат вместо неё повышение их доли в поступлениях от налога с оборота.

*** Электронный федеральный универмаг, ЭФУ (Kaufhaus des Bundes) - создан в 2004 г., на этой платформе действуют 4 центральных органа закупок (ЦОЗ) при министерстве внутренних дел, центральном таможенном управлении, Бундесвере, федеральном ведомстве материаловедения. Секретариат ЭФУ разрабатывает типовые договоры закупок (ТДЗ) и единые стандарты закупок, согласовывает процедуры присуждения закупочных контрактов и проводит модернизацию ЭФУ.

\section{Список литературы}

Грачева М. Новые технологии формулирования федерального бюджета Германии: создание независимого бюджетного института. Германия. 2017. Доклады Института Европы РАН № 354. Под ред. В.Б. Белова. М., 2018.

Грачева М. Эффективность среднесрочного планирования федеральных расходов в Германии: точность бюджетных проектировок. Научно-аналитический вестник ИЕ РАН. 2018. №6.

\footnotetext{
${ }^{1}$ OECD Recommendation..., 2015. P. 10.

Научно-аналитический вестник ИЕ РАН, 2019, №2
} 


\section{References}

Abschlussberichte zum Spending Review-Zyklus 2015/2016, 2016/2017, 2017/2018. In: Finanzberichte 2017, 2018, 2019. Bundesministerium der Finanzen. 2016, 2017, 2018.

Bach S. Spending reviews: Germany's first experiences. Bundesministerium der Finanzen. 6.07.2017.

Budget Review: Germany. OECD Journal on Budgeting. Vol. 2014/2.

Deutschlands Zukunft gestalten. Koalitionsvertrag zwischen CDU, CSU und SPD 18. Legislaturperiode. 2013.

Ein neuer Aufbruch für Europa Eine neue Dynamik für Deutschland Ein neuer Zusammenhalt für unser Land. Koalitionsvertrag zwischen CDU, CSU und SPD 19. Legislaturperiode. 2018.

Eurogroup statement - thematic discussions on growth and jobs: common principles for improving expenditure allocation. European Council. 9.09.2016.

OECD Recommendation of the council on public procurement. Paris, 2015.

Quality of public finances: spending reviews for smarter expenditure allocation in the euro area. European Commission. 15.06.2017.

Robinson M. Spending reviews. OECD Journal on Budgeting. Vol. 2013/2.

Spending reviews im Bundeshaushalt. Monatsbericht des BMF. 2016. №9.

Spending review. In: Government at a glance 2017. Paris, 2017.

Spending review. In: 2016 OECD Performance budgeting survey highlights. Paris, 2017.

Wendling C. Spending review in the European Union. IMF PFM Blog. 15.12.2016.

Wirkungsorientierung im Bundeshaushalt - mehr als Spending Reviews. Monatsbericht des BMF. 2017. №9.

\section{The Introduction of Spending Review into the Budget Process in Germany}

Author. Maria Gracheva, Candidate of Sciences (Economics), leading researcher, Primakov National Research Institute of World Economy and International Relations, Russian Academy of Sciences. Address: 23, Profsoyuznaya str., Moscow, Russia, 117997. E-mail: mgracheva@mail.ru.

Abstract. The article describes Germany's experience of the new budget technology, i.e. the spending review (SR) procedure. By 2019, it became a permanent and mandatory part of the budget preparation. SR is based on a system of interrelated concepts developed by competent experts of the OECD, the European Commission and the Eurogroup. The SR cycle lasts for one and a half years, starting annually in March and ending in August of the next year. The scope of expenses and line ministries/departments increase with each cycle. SR in Germany is focused on improving the prioritization of expenses; it is the selective one and results mainly in the functional savings. With the implementation of SR, a system of compulsory simultaneous consideration of options for saving the existing expenses and options for accepting the new commitments has been established at the level of top political leadership. This ensures compliance with the maximum limit of total expenses, which is necessary to maintain the stability of state finances.

Key words: spending review, SR, expenses prioritization, selective SR, functional savings, SR cycle.

DOI: http://dx.doi.org/10.15211/vestnikieran22019106112 